\title{
PENGARUH METODE DISCOVERY LEARNING TERHADAP KESADARAN SEJARAH PESERTA DIDIK UNTUK MENGAHADAPI REVOLUSI INDUSTRI 4.0
}

\author{
Nurul Umamah,. Sumardi, Suci Rahayu \\ Email:nurul70@unej.ac.id \\ Pendidikan Sejarah, Fakultas Keguruan dan Ilmu Pendidikan, Universitas Jember
}

\begin{abstract}
Abstrak
Discovery learning merupakan metode yang direkomendasikan dalam kurikulum 2013. Implementasinya menuntut peserta didik untuk belajar menemukan, memecahkan masalah dan menarik kesimpulan sendiri. Metode tersebut memfasilitasi peserta didik untuk berfikir kritis, bertindak kreatif, dan produktif, serta terampil dalam berkolaborasi (4C). Dalam pembelajaran peserta didik aktif mencari tahu dan tidak lagi diberi tahu. Namun fakta yang ditemukan di sekolah menunjukkan peserta didik kurang memahami dan belum dapat menemukan ide atau konsep baru secara mandiri. Dengan demikian peluang mereka untuk dapat mengambil makna belajar sejarah sangat rendah. Penelitian ini merupakan penelitian eksperimen dengan pola one group pretest-posttest design. Bertujuan untuk menganalisis perbedaan tingkat kesadaran sejarah peserta didik sebelum dan sesudah menggunakan metode discovery learning. Metode pengumpulan data dalam penelitian ini menggunakan tes. Teknik analisis data menggunakan statistik non parametik yaitu uji Wilcoxon sign rank test dengan bantuan program SPSS (Statistic Product Service Solution) versi 25. Hasil perhitungan uji Wilcoxon sign rank test diperoleh nilai rata-rata positive ranks atau selisih positif sebesar 22,50 dan nilai rata-rata negative ranks atau selisih negatif sebesar 0. Sementara nilai ties pre test dan post test sebesar 0. Kemudian hasil perhitungan test statistic diperoleh nilai $0,000<0,005$. Dari hasil perhitungan tersebut dapat disimpulkan bahwa ada pengaruh yang signifikan penggunaan metode discovery learning terhadap kesadaran sejarah peserta didik.
\end{abstract}

Kata kunci: Pembelajaran Sejarah, Metode Discovery Learning, Kesadaran Sejarah, Revolusi Industri.

\section{Pendahuluan}

Revolusi Industri 4.0 menjadi ancaman sekaligus peluang bagi perguruan Tinggi di Indonesia. Guna menghadapi tantangan tersebut Menristekdikti (2018) menjelaskan ada lima elemen penting menjadi perhatian dan akan dilaksanakan oleh Kemenristekdikti guna mendorong pertumbuhan ekonomi dan daya saing bangsa di era Revolusi Industri 4.0. Guna merealisasikan lima elemen tersebut, perguruan tinggi, termasuk di dalamnya LPTK akan mengarahkan dan melaksanakan aktivitas Tri Dharmanya guna membiasakan anak untuk berfikir kritis, bertindak kreatif dan produktif, serta terampil berkolaborasi (4C). Revolusi indutri ini juga berkaitan dengan kurikulum 2013 yang diterapkan di beberapa sekolah di Indonesia. 
Kurikulum 2013 dalam mata pelajaran sejarah mengalami beberapa penyempurnaan pola pikir. Salah satunya yaitu dari peserta didik diberi tahu menjadi mencari tahu (Kemendikbud, 2016). Peserta didik dituntut untuk menemukan fakta baru yang bermakna dalam pembelajaran sejarah. Kemampuan peserta didik tersebut dipengaruhi dari metode pembelajaran yang digunakan pendidik. Kurikulum 2013 telah memberikan rekomendasi metode pembelajaran yang dapat diterapkan pada pembelajaran sejarah yaitu problem based learning, project based learning, inquiry learning, dan discovery learning (Kemendikbud, 2016). Salah satu metode yang dapat diterapkan yaitu discovery learning, karena mampu membantu peserta didik untuk belajar secara aktif dan lebih bermakna dalam menganalisis dan memahami peristiwa sejarah (Hardiana, 2017; Sardiman, 2015). Dengan demikian dapat membantu peserta didik untuk mencapai tujuan pembelajaran sejarah secara optimal.

Discovery learning merupakan pembelajaran berbasis penemuan yang terjadi dalam situasi pemecahan masalah. Sementara peserta didik belajar dengan pengalaman dan pengetahuan yang ada untuk menemukan fakta-fakta, hubungan, dan kebenaran-kebenaran baru yang bermakna (Bruner, 1961). Pendidik hanya berperan sebagai fasilitator dan pembimbing dalam proses pembelajaran ini. Oleh karena itu, metode discovery learning tepat digunakan untuk memfasilitasi peserta didik belajar mengidentifikasi masalah, menemukan solusi permasalahan, mencari informasi yang relevan, dan mengembangkan berbagai macam solusi serta melaksanakan solusi yang dipilih (Borthick \& Jones, 2000). Metode discovery digunakan peserta didik untuk membangun pengetahuannya sendiri berdasarkan prinsip dan hasil percobaan (Joolingen, 1999). Hasil percobaan digunakan untuk membuat kesimpulan, sehingga mampu meningkatkan pengetahuan dan kompetensi dari informasi yang disajikan oleh pendidik maupun lingkungan sekitar.

Beberapa hasil penelitian ditemukan permasalahan mengenai kemampuan pendidik dalam merancang desain pembelajaran akibat paradigma baru yang membawa perubahan fundamental, salah satuya terhadap implementasi metode pembelajaran (Umamah, 2018). Sejalan dengan hal tersebut, dalam penelitian Umamah (2008) disebutkan bahwa kemampuan pendidik dalam mengembangakan desain pembelajaran didasarkan pada 15,4\% penelitian, 69,2\% pengalaman, dan 15,4\% berdasarkan lainnya. Dengan demikian, data tersebut menunjukkan bahwa kemampuan pendidik dalam mendesain pembelajaran didasarkan pada pengalaman, 
sehingga kurang membantu peserta didik untuk mengembangkan kemampuan menemukan dan memecahkan masalah sesuai dengan tuntutan kurikulum 2013.

Selama ini masih banyak pendidik mengimplementasikan metode pembelajaran ceramah, diskusi, dan lain-lain yang menyebabkan peserta didik menjadi bosan terhadap materi sejarah (Hardiana, 2017; Sayono, 2013; Sardiman, 2015). Hal ini juga diperparah dengan image pembelajaran sejarah yang selalu bersifat menghafal, kurang menarik, sulit, dan membosankan (Umamah, 2017; Rosita, dkk., 2018). Sehingga diperlukan peran pendidik sebagai fasilitator dan perancang (desaigner) untuk proses pembelajaran sejarah.

Pembelajaran sejarah yang ideal mampu memfasilitasi peserta didik untuk mencapai tujuan pembelajaran sejarah secara optimal (Na'im, dkk, 2017; Sayono, 2013). Namun, lingkup materi pembelajaran sejarah yang ditemukan dalam BSE kurang detail dan penjelasannya sesuai dengan SK dan KD pada kurikulum 2013 yaitu materi sejarah nasional (Umamah, 2018; Ma'unah, dkk., 2018; Jumianto \& Prasetyo, 2015). Bahkan materi sejarah lokal belum dikenalkan dalam Buku Paket dan LKS yang menjadi referensi utama peserta didik (Aprianto, dkk., 2017; Pratiwi, 2017). Sejalan dengan hal itu, pendidik juga mengatakan kurangnya waktu yang diberikan pemerintah untuk menjelaskan materi sejarah lokal (Silvi, 2014). Sementara itu, hasil telaah KD pada KI-3 (tingkat pengetahuan) kelas X SMA mata pelajaran sejarah diketahui 57\% ranah kognitif mencapai level $\mathrm{C} 4$ yaitu menganalisis.

Dimensi proses kognitif menganalisis wajib dikuasai oleh peserta didik agar tujuan pembelajaran sejarah dapat tercapai maksimal. Salah satu tujuan pembelajaran sejarah yaitu menumbuhkembangkan kesadaran dalam diri peserta didik sebagai bagian dari bangsa Indonesia yang memiliki rasa bangga dan cinta tanah air, melahirkan empati dan perilaku toleran yang dapat diimplementasikan dalam berbagai kehidupan masyarakat dan bangsa (Kemendikbud, 2015:11). Penanaman kesadaran sejarah kepada peserta didik mudah dilakukan dengan memperkenalkan sejarah di lingkungannya, sehingga dapat menghindarkan keterasingan lingkungan (Umamah, 2016; Abduh, 2015; Widja, 1991). Lingkungan menjadi salah satu kategori yang dapat dimanfaatkan sebagai sumber pembelajaran (Ma'unah, dkk., 2018). Hal ini juga didukung dalam Permendikbud 79 tahun 2014 tentang Muatan Lokal Kurikulum 2013 memiliki tujuan untuk membekali peserta didik mengenal dan mencintai lingkungan alam, sosial, budaya, dan spiritual di daerahnya (Permendikbud, 2014). 
Materi sejarah lokal memiliki sifat otonom menjadi jembatan penghubung antara micro history dan macro history (Wibowo, 2016; Widja, 1989). Hubungan antara sejarah lokal (micro history) dengan sejarah nasional (macro history) menunjukkan bagian tertentu dari masyarakat setempat yang terpisah, tetapi juga menjadi bagian secara keseluruhan dari sejarah nasional (Widja, 1991). Pengintegrasian sejarah lokal dalam kurikulum 2013 memiliki 100\% peluang untuk pembelajaran sejarah (Umamah, 2016). Sejarah lokal dapat memperkenalkan dan memberikan pemahaman mengenai potensi sejarah dan budaya daerahnya masing-masing kepada peserta didik.

Berdasarkan hasil performance analysis yang diadaptasi dari Umamah (2014) dapat diidentifikasi analisis kebutuhan dan kesenjangan terkait pembelajaran sejarah di tiga SMAN Kabupaten Jember menunjukkan bahwa: (1) pelaksanaan pembelajaran sejarah yang kurang mengaitkan dengan kebutuhan lingkungan sekitar, karena 100\% sumber belajar yang digunakan pendidik dan peserta didik berupa LKS dan Buku Paket dengan materi sejarah nasional; (2) cukup tingginya motivasi belajar peserta didik terhadap sejarah lokal yang terlihat dari hasil analisis data dengan persentase 52,78\%; (3) $60 \%$ pendidik menggunakan metode pembelajaran ceramah dan diskusi, sementara $20 \%$ pendidik menggunakan metode discovery learning, namun belum dilaksanakan sesuai sintaks. Dengan demikian, untuk mengatasi permasalahan tersebut, maka dilakukan penelitian eksperimen terkait pengaruh metode discovery learning terhadap kesadaran sejarah peserta didik.

Penelitian eksperimen ini memiliki tujuan yaitu mengetahui adanya pengaruh signifikan metode discovery learning terhadap kesadaran sejarah peserta didik untuk menghadapi revolusi industri 4.0. Adapun manfaat bagi pendidik yaitu dapat memberikan solusi untuk meningkatkan kesadaran sejarah peserta didik melalui metode discovery learning. Manfaat penelitian bagi akademisi dan para peneliti yaitu penelitian diharapkan dapat menjadi bahan informasi serta kajian bagi pengembangan penelitian selanjutnya.

\section{Metode}

Metode penelitian yang digunakan dalam penelitian ini adalah ekperimen. Dalam penelitian ini digunakan satu kelompok sampel peserta didik yang diberikan pre test kemudian diberikan perlakuan tertentu. Pengukuran selanjutnya, peserta didik diberikan post test. Desain dalam penelitian ini adalah one group pretest-posttest design yaitu rancangan yang digunakan 
dalam satu kelompok dengan pre test sebelum diberikan perlakuan dan post test sesudahnya, kemudian hasilnya dapat diketahui lebih akurat karena dapat membandingkan dengan keadaan sebelum diberikan perlakuan. Berikut ini gambar desain penelitian one group pretest-posttest design.

Gambar 1. Desain penelitian one group pretest-posttest design

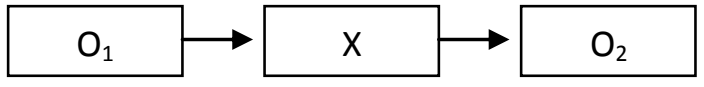

Keterangan :

$\mathrm{O}_{1} \quad$ : Nilai pre test (sebelum diberikan perlakuan)

$\mathrm{O}_{2} \quad$ : Nilai post test (setelah diberikan perlakuan)

$\mathrm{X} \quad$ : Eksperimen (perlakuan yang diterapkan)

(Sugiyono, 2015)

Seluruh peserta didik kelas X di SMAN Kabupaten Jember Tahun Pelajaran 2018/2019 yang terdiri dari tiga kelas IIS memperoleh hasil belajar sejarah yang berbeda-beda. Berikut ini tabel hasil belajar sejarah peserta didik kelas X IIS di SMAN Kabupaten Jember.

Tabel 1. Hasil Belajar Sejarah Peserta Didik Kelas X IIS

\begin{tabular}{lll}
\hline No. & Kelas & Rata-rata Hasil Belajar \\
\hline 1. & X IIS 1 & 78,5 \\
2. & X IIS 2 & 76,8 \\
3. & X IIS 3 & 75,2 \\
\hline Jumlah & & 231 \\
\hline
\end{tabular}

(Sumber: data primer diolah)

Berdasarkan tabel di atas, pengambilan sampel dilakukan dengan menggunaka teknik random sampling. Penarikan sampel pada penelitian ini adalah dengan cara mengundi kelas $\mathrm{X}$ IIS di SMAN Kabupaten Jember untuk menentukan kelas untuk penelitian. Penelitian dilakukan di SMAN Kabupaten Jember pada semeseter genap tahun pelajaran 2018/2019. Metode pengumpulan data dalam penelitian ini menggunakan tes dan kuesioner untuk mengukur tingkat kesadaran sejarah peserta didik. Subjek penelitian ini yaitu 1 pendidik dan 44 peserta didik kelas 405 | Seminar Nasional Sejarah ke 4 Jurusan Pendidikan Sejarah Universitas Negeri Padang 
X IIS di SMAN Kabupaten Jember. Teknik analisis data menggunakan statistik non parametik yaitu uji Wilcoxon (wilcoxon sign rank test) dengan bantuan program SPSS versi 25.

\section{Hasil dan Pembahasan}

Penelitian ini dilakukan pada kelas X IIS di SMAN Kabupaten Jember. Subjek 44 peserta didik sebagai sampel akan diberikan pre test dan post test dengan 10 item soal. Data dari pre test dan post test akan dianalisis uji perbedaan kesadaran sejarah peserta didik sebelum dan sesudah menggunakan metode discovery learning melalui uji Wilcoxon (Wilcoxon signed rank test). Berikut ini hasil pengujian Wilcoxon menggunakan SPSS.

Tabel 2. Hasil Ranks

\begin{tabular}{llrrr}
\hline & & $\mathrm{N}$ & Mean Rank & Sum of Ranks \\
\hline pre test-post test & Negative Ranks & $0^{\mathrm{a}}$ &, 00 &, 00 \\
& Positive Ranks & $44^{\mathrm{b}}$ & 22,50 & 990,00 \\
& Ties & $0^{\mathrm{c}}$ & & \\
& Total & 44 & & \\
& & & post test $<$ pre test \\
a. & & post test $>$ pre test \\
b. & & post test $=$ pre test
\end{tabular}

(Sumber: data primer diolah)

Berdasarkan tabel 2. Hasil Ranks di atas diketahui bahwa negative ranks atau selisih negatif antara tingkat kesadaran sejarah untuk pre test dan post test adalah 0 , baik itu pada nilai $\mathrm{N}$, mean ranks, maupun sum ranks. Nilai 0 tersebut menunjukkan tidak adanya penurunan (pengurangan) dari nilai pre test dan post test. Kemudian positive ranks atau selisih positif antara tingkat kesadaran sejarah untuk pre test dan post test. Nilai $\mathrm{N}$ data positif yaitu 44 yang artinya ke-44 peserta didik mengalami peningkatan kesadaran sejarah dari nilai pre test dan post test menggunakan metode discovery learning. Mean ranks atau rata-rata peningkatan tersebut adalah sebesar 22,50, sedangkan jumlah positive ranks atau sum ranks sebesar 990,00. Sementara nilai ties yaitu nilai kesamaan pre test dan post test sebesar 0. Sehingga tidak dapat dikatakan bahwa tidak ada nilai yang sama antara pre test dan post test.

Tabel 3. Test Statistics ${ }^{a}$

post test - pre test

406 | Seminar Nasional Sejarah ke 4 Jurusan Pendidikan Sejarah Universitas Negeri Padang 
\begin{tabular}{ll}
\hline $\mathrm{Z}$ & $-5,817^{\mathrm{b}}$
\end{tabular}

Asymp. Sig. (2-tailed) $\quad 000$

a. Wilcoxon Signed Ranks Test

b. Based on negative ranks.

(Sumber: data primer diolah)

Berdasarkan tabel 3. Test Statistic di atas diketahui nilai Z sebesar $-5,817$ pada taraf signifikansi 5\%. Hal ini menunjukka $Z_{\text {hitung }}$ lebih kecil dari nilai $Z_{\text {tabel }}$. Sementara hasil perhitungan data statistik diperoleh, Asymp. Sig (2-tailed) bernilai 0,000. Karena nilai 0,000 lebih kecil dari 0,005 $(0,000<0,005)$, maka $\mathrm{H}_{0}$ ditolak dan $\mathrm{H}_{\mathrm{a}}$ diterima. Artinya ada perbedaan antara tingkat kesadaran sejarah peserta didi untuk pre test dan post test. Dengan demikian, dapat disimpulkan bahwa terdapat pengaruh penggunaan metode discovery learning terhadap tingkat kesadaran sejarah peserta didik.

Proses pembelajaran sejarah menggunakan metode discovery learning bertujuan agar peserta didik mampu menganalisis masalah dengan menemukan konsep yang bermakna. Peserta didik diharapkan mampu mencari dan menemukan ide baru yang bermakna terkait sejarah lokal yang ada di lingkungan sekitar peserta didik. Hal ini juga berkaitan dengan revolusi industri 4.0 untuk menuntut adanya keterampilan 4C (communication, collaboration, critical thinking and problem solving). Sebab melalui belajar penemuan secara mandiri,maka peserta didik dengan mudah mengingat dan memahami informasi yang diperoleh. Dengan demikian tingkat kesadaran sejarah peserta didik bisa meningkat melalui belajar menemukan fakta dan ide baru yang bermakna secara mandiri.

Kesadaran sejarah peserta didik dapat dibangun melalui pencapaian pemahaman pembelajaran sejarah dan pemikiran sejarah ketika proses pembelajaran di kelas (Ramdhani, dkk., 2019). Aktualisasi nilai-nilai kesadaran sejarah dalam pembelajaran sejarah ditunjukkan melalaui upaya: (a) penanaman penghayatan arti penting sejarah untuk masa kini dan mendatang; (b) mengenal diri sendiri dan bangsanya; (c) pembudayaan sejarah bagi pembinaan budaya bangsa; dan (d) menjaga peninggalan sejarah bangsa (Aman, 2014). Tingkat kesadaran sejarah dapat diketahui melalui pengalaman individu seperti unit makro yaitu lingkungan sekitar (Vubo, 2003). Kesadaran sejarah merupakan kunci konsep penting dan signifikan dalam didaktik sejarah (Throrp, 2014; Korber, 2015). Kesadaran sejarah perlu dilakukan dengan tujuan untuk memperluas pengetahuan sejarah dan pemahaman nilai sejarah budaya bangsa. 
Pengetahuan sejarah peserta didik dapat dibuktikan melalui temuan dalam pembelajaran sejarah (Kreuzer, 2010). Kemudian hasil tersebut dapat memperkuat kesadaran sejarah dan bahkan dapat membedakan antara fakta dan mitos kesadaran sejarah (Pompa, 1990). Kesadaran sejarah membantu peserta didik untuk mencari makna yang tercermin dalam peristiwa sejarah. Hal ini perlu dilakukan peserta didik agar menambah pengetahuan dan pemahaman sejarah. Dengan demikian, dalam proses pembelajaran pendidik juga harus mengimplementasikan metode pembelajaran seperti discovery learning yang menuntut peserta didik belajar aktif menemukan konsep dengan pengetahuan yang bermakna.

Pembelajaran menggunakan metode discovery learning dapat membantu peserta didik untuk mengeksplorasi, memperoleh data spesifik, memproses informasi, dan menarik kesimpulan (Dewi, dkk., 2014; Safitri, dkk., 2019). Metode discovery learning merupakan metode pembelajaran alternatif yang dapat memfasilitasi peserta didik untuk terlibat aktif dalam proses pembelajaran sejarah dengan ide atau fakta atau kebenaran baru yang bermakna (Muzayana, dkk., 2014; Kyriazis, dkk., 2009). Metode ini merupakan metode pembelajaran konstruktivis yang menyediakan kesempatan kepada peserta didik untuk mengeksplorasi dan menemukan konsep mereka sendiri menggunakan pendekatan pemecahan masalah. Peserta didik dapat secara aktif belajar secara bermakna dengan pengetahuannya sendiri melalui kegiatan sesuai metode ilmiah (Safitri, dkk., 2019). Discovery learning melibatkan peserta didik untuk menemukan sendiri permasalahan, pemecahan masalahnya, dan akhirnya menemukan konsep yang lebih bermakna (Priyanti, dkk., 2015). Sehingga peserta didik mudah mengingat dan memahami pengetahuan sejarah yang ditemukan secara mandiri.

Metode discovery learning dapat meningkatkan hasil belajar secara keseluruhan baik dari segi pengetahuan, sikap, dan keterampilan (Safitri, 2019; Dewi, 2014; Muzayana, 2014). Metode discovery learning menurut Kemendikbud (2013) memiliki kelebihan diantaranya: (a) membantu peserta didik untuk memperbaiki dan meningkatkan keterampilan-keterampilan dan proses kognitif; (b) mendorong peserta didik untuk memahami dan merumuskan hipotesisi sendiri; (c) peserta didik akan mengerti konsep dasar dan ide-ide yang baik; dan (d) mengarahkan kegiatan belajar peserta didik secara mandiri dengan melibatakan akal dan motivasi sendiri. Berdasarkan kelebihan dari metode discovery learning, maka dapa membantu peserta didik untuk belajar sejarah secara aktif melalui penemuan ide atau fakta yang bermakna. Peserta didik dapat belajar sejarah melalui lingkungan sekitar, sehingga mereka bisa menemukan dan memahami 
pengetahuan sejarah yang bermakna. Selain itu, peserta didik mampu mengingat peristiwa sejarah yang ada di lingkungan sekitar dengan mudah dan bisa lebih bermakna.

\section{Simpulan}

Berdasarkan hasil analisis data, pembahasan yang telah disajikan dapat disimpulkan bahwa ada pengaruh signifikan dari metode discovery learning terhadap kesadaran sejarah peserta didik. Hasil perhitungan statistik menunjukkan mean ranks atau rata-rata peningkatan sebesar 22,50. Adapun hasil perhitungan Test Statistic diketahui nilai Asymp. Sig (2-tailed) bernilai 0,000. Karena nilai 0,000 lebih kecil dari 0,005 $(0,000<0,005)$, maka $\mathrm{H}_{0}$ ditolak dan $\mathrm{H}_{\mathrm{a}}$ diterima. Artinya ada pengaruh perbedaan tingkat kesadaran sejarah peserta didik pre test dan post test dalam penggunaan metode discovery learning. Dengan demikian, dapat disimpulkan bahwa terdapat pengaruh penggunaan metode discovery learning terhadap tingkat kesadaran sejarah peserta didik di SMAN Kabupaten Jember.

\section{DAFTAR PUSTAKA}

Abduh, M. (2015). Pengembangan Media Pembelajaran Tematik-Integratif Berbasis Sosiokultural, 2(2), 121-132.

Aprianto, D., dkk. (2017). Development of E-Learning Module: Historical Culture Society Based on Local Genius, Jurnal HISTORICA, 1(2252), 152-168.

Borthick, A. F., \& Jones, D. R. (2000). The Motivation for Collaborative Discovery Learning Online and Its Application in an Information Systems Assurance Course, 15(2).

Bruner, J.S. (1961). The Act Discovery. Harvard Ed. 31 : 1-9.

Dewi, E.R., dkk. (2014). Penerapan Metode Discovery Learning Berbasis Asesment Produk untuk Meningkatkan Hasil Belajar Peserta Didik pada Mata Pelajaran Sejarah Kelas X IIS 1 di SMA Negeri 5 Jember Tahun Ajaran 2014/2015. Jurnal Pendidikan UNEJ, 1(1): 1-8.

Hardiana, Y. (2017). Pembelajaran Sejarah Indonesia Berbasis Peristiwa-Peristiwa Lokal Di Tasikmalaya untuk Meningkatkan Kemampuan Berpikir Kritis. Jurnal HISTORIA: Pendidik dan Peneliti Sejarah,XV(1).

Joolingen, W.V. (1999). Cognitive Tools For Discovey Learning. International Journal Of Artificial Intelligence In Education (IJAIED), 10:385-397.

409 | Seminar Nasional Sejarah ke 4 Jurusan Pendidikan Sejarah Universitas Negeri Padang 
Kemendikbud. (2013). Model Pembelajaran Penemuan (Discovery Learning). Jakarta: Kementerian Pendidikan dan Kebudayaan.

Kemendikbud. (2015). Materi Pelatihan Guru Implementasi Kurikulum 2013 Tahun 2015 Mata Pelajaran Sejarah SMA/SMK. Jakarta: Badan Pengembangan Sumber Daya Manusia Pendidikan dan Kebudayaan.

Kemendikbud. (2016). Silabus Mata Pelajaran Sekolah Menengah Atas/Sekolah Menengah Kejuruan/Madrasah Aliyah/Madrasah Aliyah Kejuruan (SMA/SMK/MA/MAK): Mata Pelajaran Sejarah Indonesia. Jakarta: Kementerian Pendidikan dan Kebudayaan.

Korber, A. (2015). Historical Consciousness, Historical Competencies-and Beyond? Some Conceptual Development within German History Didactics. URN: urn:nbn:de:0111-pedocs-108118.

Kreuzer, M. (2010). Historical Knowledge and Quantitative Analysis: The Case oh the Origins of Proportional Representation. American Politicl Science Review, 104(2).

Kyriazis, A., dkk. (2009). Discovery Learning and the Computational Experiment in Higher Mathematics and Science Education: A Combined Approach. iJET, 4 Issue 4.

Margana, S. (2012). Ujung Timur Jawa, 1763-1813: Perebutan Hegemoni Blambangan. Yogyakarta: Pustaka Ifadi.

Ma'unah, S., dkk. (2018). The Enhancement of Attractiveness and Effectiveness of History Learning Using Local History Interactive Teaching Material, American Journal of Educational Research, 6(1).

Menristekdikti. (2018). https://www.ristekdikti.go.id/pengembangan-iptek-dan pendidikantinggi-di-era-revolusi-industri-4-0 2/\#AWDcVe62e6B4GLJW.99 diakses 20 Agustus 2018.

Muzayana, dkk. (2014). Penerapan Metode Pembelajaran Discovery untuk Meningkatkan Keaktifan dan Kreativitas Belajar Sejarah Peserta Didik Kelas XI IPA 4 MAN Lumajang Tahun Ajaran 2013/2014. Artikel Ilmiah Mahasiswa, 1(1): 1-7.

Na'im, M., dkk. (2017). Upaya Meningkatkan Aktivitas dan Hasil Belajar Penerapan Melalui Model Pembelajaran Kooperatif Tipe Group Investigation pada Mata Pelajaran Sejarah. Jurnal Pendidikan dan Humaniora, 55(1). 
Pratiwi, U.D. (2017). Pengembangan Modul Sejarah Lokal Pamekasan (1945-1950) Sebagai Penunjang Kompetensi Dasar 3.10 dan 4.10 Kelas XII MIPA 2 SMAN 2 Pamekasan. Skripsi. Malang: Universitas Negeri Malang.

Priyanti, dkk. (2015). Penerapan Metode Pembelajaran Discovery Berbasis Authentic Assessment untuk Meningkatkan Kemampuan Berpikir Kritis dan Hasil Belajar Sejarah Peserta Didik Kelas X SMK Negeri 5 Jember Tahun Ajaran 2014/2015. Artikel Ilmiah Mahasiswa, 1(1): 1-9.

Permendikbud. (2014). Peraturan Menteri Pendidikan dan Kebudayaan Republik Indonesia Nomor 79 Tahun 2014 Tentang Muatan Lokal Kurikulum 2013. Jakarta: Menteri Pendidikan dan Kebudayaan.

Pompa, L. (1992). Human Nature and Historical Knowledge: Hume, Hegel, and Vico. History and Theory, 31(1), pp. 56-65.

Ramdhani, A.M., dkk. (2019). Developing Student's Historical Consciousness by Understanding the Indonesian History and the Historical Thinking. IOP Conference Series: Earth and Environmentl Science, 243.

Rosita, R., dkk. (2018). Improving the High School Students' Appeal and Effectiveness the History Learning Through Inquiry Based Digital Module Design. Social Science Learning Education Journal, 3(2456).

Safitri, D.A., dkk. (2019). Accelerated Learning Integrated by Discovery Learning in History Course: How Z Generation Learn. IOP Conference Series: Earth and Environmentl Science, 243.

Sardiman, A.M. (2015). Menakar Sejarah Indonesia pada Kurikulum 2013. Jurnal, XI(1), 10

Sayono, J. (2013). Pembelajaran Sejarah Di Sekolah dari Pragmatis Ke Idealis. Jurnal Sejarah dan Budaya, 7(1).

Silvi, D. O., dkk. (2014). Pengembangan Bahan Ajar Sejarah Kerajaan Lamajang Tigang Juru Tahun 1294 M-1316 M dalam Pembelajaran Sejarah Di SMA (Sekolah Menengah Atas) dengan Menggunakan Model ADDIE, 1-10.

Sugiyono. (2015). Metode Penelitian Pendidikan (Pendekatan Kuantitatif, kualitatif, dan $R \&$ $D)$. Bandung: Alfabeta.

Thorp, R. (2014). Historical Consciousness and Historical Media - A History Didactical Approach to Educational Media. Educational Inquiry, 5(4), pp. 497-516.

411 | Seminar Nasional Sejarah ke 4 Jurusan Pendidikan Sejarah Universitas Negeri Padang 
Umamah, N. (2008). Kemampuan Guru dalam Mengembangkan Desain Pembelajaran IPS SD se-Eks Kotatif Jember Tahun 2008. Jurnal Ilmu Pendidikan Sekolah Dasar, 1(1).

Umamah, N. (2016). Integrasi Sejarah Lokal dalam Kurikulum Sejarah SMA Peluag dan Kendala (Studi Kasus Pengembangan Kurikulum SMA di Kabupaten Jember). Prosiding Seminar Nasional Sejarah Lokal. 11-12 November 2016. Universitas Indonesia: Program Studi Ilmu Sejarah Fakultas Ilmu Pengetahuan Budaya: 349.

Umamah, N. (2017). Pembelajaran Sejarah Kesiapannya Menghadapi Tantangan Zaman. Prosiding Kapita Selekta (Pendidikan) Sejarah Indonesia. 14-16 Desember 2017. Yogyakarta: Ombak:192.

Umamah, N. (2018). Perkembangan Kurikulum Pendidikan Sejarah di Indonesia Peluang Pengembangan Sejarah Lokal. Makalah dalam Sarasehan Sejarah Lokal Jawa Timur Tahun 2018. Dinas Kebudayaan dan Pariwisata Jawa Timur.

Vubo, E.Y. (2003). Levels of Historical Awareness: The Development of Identity and Ethnicity in Cameroon. Cahiers d'Etudes Africaines, XLIII (3), pp. 591-628.

Wibowo, A.M. (2016). Pengembangan Model Pembelajaran Sejarah Lokal Di SMA Kota Madiun. Jurnal AGASTYA, Vol 6 (1).

Widja, I.G. (1989). Dasar-Dasar Pengembangan Strategi serta Metode Pengajaran Sejarah. Jakarta: Departemen Pendidikan dan Kebudayaan Direktorat Jenderal Pendidikan Tinggi Proyek Pengembangan Lembaga Pendidikan Tenaga Kependidikan.

Widja, I. G. (1991). Sejarah Lokal Suatu Persektif dalam Pengajaran Sejarah. Bandung: Angkasa. 